\title{
ANTIOXIDANT NAPHTHOQUINONES OF Sinningia reitzii FROM SANTA CATARINA STATE, BRAZIL
}

\author{
Vanessa Winiewski ${ }^{a}$, Adson S. Silva ${ }^{a}$, Kattleen D. C. Alvarez ${ }^{b}$, Eduardo L. de Sáa Marcos J. Salvador ${ }^{\mathrm{b}}$ and Maria Élida \\ A. Stefanello ${ }^{\mathrm{a}, *,(0)}$ \\ aDepartamento de Química, Universidade Federal do Paraná, 81530-900 Curitiba - PR, Brasil \\ ${ }^{b}$ Departamento de Biologia Vegetal, Instituto de Biologia, Universidade Estadual de Campinas, 13083-970 Campinas - SP, Brasil
}

Recebido em 25/07/2020; aceito em 26/10/2020; publicado na web em 01/12/2020

\begin{abstract}
Sinningia reitzii (Hoehne) L. E. Skog (Gesneriaceae) is a subshrub native to Brazil, where it is distributed in two disjunctive populations around the $26^{\circ} \mathrm{S}$ and $23^{\circ} \mathrm{S}$ parallels. In this work, tubers of plants from the wild population growing at the $26^{\circ} \mathrm{S}$ parallel (Santa Catarina state) yielded two new naphthoquinones, 5,6-dihydroxy-7-methoxy- $\alpha$-dunnione and 8-hydroxy-6,7-dimethoxy$\alpha$-dunnione. Three known compounds were also isolated: 6,8-dihydroxy-7-methoxy- $\alpha$-dunnione, 5 -hydroxy-6,7-dimethoxy- $\alpha$ dunnione, and 6,8-dihydroxy-7-methoxy-2-O-methyldunniol. The naphthoquinones 6,8-dihydroxy-7-methoxy-2-O-methyldunniol, 6,8-dihydroxy-7-methoxy- $\alpha$-dunnione, and 5,6-dihydroxy-7-methoxy- $\alpha$-dunnione displayed antioxidant activity in the ORAC-FL method, with values of relative trolox equivalent in the range of $1.39-4.83 \mu \mathrm{mol} \mathrm{g}^{-1}$.
\end{abstract}

Keywords: Gesneriaceae; Sinningia reitzii; naphthoquinones; antioxidant activity.

\section{INTRODUCTION}

The neotropical genus Sinningia (Gesneriaceae) comprises more than 70 species distributed from Mexico to Argentina, of which 75 species are recognized as native to Brazil. The genus is found in several biomes, but most species occur in the Atlantic Forest of the Southeast region of the country. ${ }^{1,2}$

The chemical constituents reported to date in Sinningia are typical for members of the Gesneriaceae family. Caffeoyl ethanoid glycosides, which are widely distributed in Gesneriaceae, have been reported from ethanolic extracts of several Sinningia species. Other compound classes, such as triterpenes, sesquiterpenes, flavonoids, anthraquinones, naphthoquinones and derivatives, have been isolated from less polar extracts of Sinningia and of other Gesneriaceae genera. ${ }^{3,4}$

Sinningia reitzii (Hoehne) L. E. Skog, known as "cachimbo", is a perennial subshrub with tubers endemic to Brazil. The plant measures $30-120 \mathrm{~cm}$ in height, and has dark green leaves with red veins on the abaxial surface; the red color also covers the entirety of the abaxial surface area in some specimens. The plants produce tubular magenta flowers from January to July. ${ }^{5}$

The geographic distribution of $S$. reitzii is discontinuous, with two isolated populations being reported. ${ }^{1}$ The first one, called S. reitzii "SC" in this work, occurs in Southern Brazil, in the area around the $26^{\circ} \mathrm{S}$ parallel, in the Santa Catarina State. The first description of S. reitzii (as Rechsteineria reitzii) was made from a specimen belonging to this population. ${ }^{6}$ The second population (referred to as $S$. reitzii "PR" in this work) is located around the $23^{\circ} \mathrm{S}$ parallel, with several records in the São Paulo State and one record in the Paraná State. ${ }^{5}$

Previous phytochemical studies of the tubers from S. reitzii "PR" have reported the isolation of twelve prenylated naphthoquinones with different framework, from the less polar extracts. Among them, two dunnione-type naphthoquinones deserve to be highlighted for their biological properties. Anti-inflammatory and anti-nociceptive activities were found for 8 -hydroxydehydrodunnione, ${ }^{7}$ while 6,7-dimethoxydunnione showed cytotoxicity against PC-3 (prostate) and HeLa (cervix) human tumor cell lines. ${ }^{8}$

\footnotetext{
*e-mail: elida@ufpr.br
}

Considering that the geographic isolation of populations of plants from the same species can lead to development of chemical varieties within the species, we decided to study the less polar chemical constituents from tubers of $S$. reitzii "SC", which had not been investigated yet. In addition, antioxidant activity was evaluated for three isolated compounds.

\section{EXPERIMENTAL}

\section{General procedures}

Optical rotations were measured in $\mathrm{CHCl}_{3}$ on a JASCO PTC203 polarimeter $\left(\lambda=589 \mathrm{~nm}\right.$, temperature $\left.=20^{\circ} \mathrm{C}\right)$. Optical density was measured using a Synergy 2 (Bio-Tek) spectrophotometer. $\mathrm{UV}$ spectra were obtained in $\mathrm{CHCl}_{3}$ on a Shimadzu UV-2401PC spectrophotometer. Circular dichroism (CD) spectra were recorded in a Jasco J-815 CD spectrometer. IV spectra were recorded on a Bruker Vertex 70/70v FTIR spectrophotometer over the range of $4000-500 \mathrm{~cm}^{-1}$. One-dimensional $\left({ }^{1} \mathrm{H},{ }^{13} \mathrm{C}\right)$ and two-dimensional (gHSQC, gHMBC) NMR spectra were recorded on Bruker spectrometers (Avance 400 and/or Avance 600) observing ${ }^{1} \mathrm{H}$ at 400 or $600 \mathrm{MHz}$, and ${ }^{13} \mathrm{C}$ at 100 or $150 \mathrm{MHz}$. Deuterated chloroform $\left(\mathrm{CDCl}_{3}\right)$ was used as solvent. Chemical shifts are given in ppm $(\delta)$, with coupling constants $(J)$ in Hz. TMS was used as internal reference. High-resolution electrospray ionization mass spectrometry (HRESIMS) data were obtained on a Bruker Micromass ESI Q-TOF mass spectrometer. Geometry optimization and density functional theory (DFT) calculations on the electronic structure of the compounds employed B3LYP functional, having Los Alamos ECP as basis set as implemented in the Gaussian suite program. ${ }^{9}$ HPLC separations were performed in a Waters apparatus equipped with PDA detector and a semi-preparative Nucleosil 100-5 C18 column $(250 \times 10 \mathrm{~mm})$. Acetonitrile:water $(60: 40$ or $50: 50$, isocratic) was used as mobile phase, with a flow rate of $2.8 \mathrm{~mL} \mathrm{~min}^{-1}$ applied for $25 \mathrm{~min}$ at room temperature. The column effluent was monitored over the 210-400 nm range. Column chromatographic separations (CC) were carried on silica gel 60 (Merck, 230-400 mesh), while precoated silica gel $60 \mathrm{GF}_{254}$ plates (Macherey-Nagel) were used for TLC analyses. Compounds were visualized by exposure under $\mathrm{UV}_{254 / 365}$ light and 
spraying with $5 \%(\mathrm{v} / \mathrm{v}) \mathrm{H}_{2} \mathrm{SO}_{4}$ in ethanol solution, followed by heating on a hot plate. All solvents were analytical or spectroscopic grade, and the mixtures of solvents were prepared as $\mathrm{v} / \mathrm{v}$.

\section{Plant material}

Tubers of Sinningia reitzii (Hoehne) L. E. Skog were collected in Corupá, Santa Catarina State, Brazil (26²4'10.9” S; 49¹7'17.54” W), in November/2018. The plant was identified by Mauro Peixoto, and a voucher specimen was deposited in the Herbarium of Universidade Federal do Paraná (UPCB 93050). The access was registered on SISGEN under number AF5C97F.

\section{Extraction and isolation}

Dried and powdered tubers of S. reitzii "SC" (53.2 g) were extracted with $\mathrm{CH}_{2} \mathrm{Cl}_{2}$ (four successive extractions employing, each time, $500 \mathrm{~mL}$ of solvent) at room temperature. The solvent was removed under reduced pressure to give the dichloromethane extract (387.1 mg). An aliquot $(50 \mathrm{mg})$ of the extract was reserved.

The remaining extract $(337.1 \mathrm{mg})$ was submitted to $\mathrm{CC}$ eluted with mixtures of Hex:EtOAc $(7: 3 ; 3: 2 ; 1: 1 ; 3: 7)$, EtOAc and $\mathrm{MeOH}$, yielding 10 fractions after TLC analysis $\left(\mathrm{F}_{1-10}\right)$. Fraction $\mathrm{F}_{4}(33.6 \mathrm{mg}$; eluted with Hex:EtOAc 7:3) was further purified by semi-preparative HPLC using $\mathrm{H}_{2} \mathrm{O}$ :MeCN 40:60 as mobile phase. The sample was dissolved in $4 \mathrm{~mL}$ of $\mathrm{MeCN}$, and 20 aliquots of $200 \mu \mathrm{L}$ were injected. This procedure yielded $\mathbf{3}(2.1 \mathrm{mg}$; Retention time $11.1 \mathrm{~min})$, 2 (0.8 mg; $\left.\mathrm{R}_{\mathrm{t}} 17.44 \mathrm{~min}\right), \mathbf{5}\left(1.7 \mathrm{mg} ; \mathrm{R}_{\mathrm{t}} 18.50 \mathrm{~min}\right)$ and 4 (1.0 mg; $\left.\mathrm{R}_{\mathrm{t}} 20.39 \mathrm{~min}\right)$. Fraction $\mathrm{F}_{5}(33.3 \mathrm{mg}$, eluted with Hex:EtOAc 7:3) yielded 3. Fraction $\mathrm{F}_{7}$ (17.6 mg; eluted with Hex:EtOAc 1:1) was purified by semi-preparative HPLC $\left(\mathrm{H}_{2} \mathrm{O}: \mathrm{MeCN} 50: 50\right)$. The sample was dissolved in $2 \mathrm{~mL}$ of $\mathrm{MeCN}$, and 10 aliquots of $200 \mu \mathrm{L}$ were injected to give $\mathbf{1}\left(3.2 \mathrm{mg} ; \mathrm{R}_{\mathrm{t}} 17.78 \mathrm{~min}\right)$ and $\mathbf{3}\left(1.1 \mathrm{mg}, \mathrm{R}_{\mathrm{t}} 18.93 \mathrm{~min}\right)$.

\section{Antioxidant activity by ORAC-FL assay}

The antioxidant capacity of the samples was measured using the Oxygen Radical Absorbance Capacity (ORAC) assay, with fluorescein (FL) as the fluorescent probe and AAPH [2,2'-azobis(2amidiopropane) dihydrochloride] as a free radical source. The experiments were carried on 96 wells plates as previously reported. ${ }^{10}$ Briefly, several dilutions of the samples $(12.5-200 \mu \mathrm{M})$ were prepared in phosphate buffer. Trolox (6-hydroxy-2,5,7,8-tetramethylchroman2-carboxylic acid) was used as a standard, being analysed at concentrations of $12.5,25,50,100$ and $200 \mu \mathrm{M}$. The reading was performed using a fluorescent filter (excitation $\lambda=485 \mathrm{~nm}$ and emission $\lambda=528 \mathrm{~nm}$ ) in a microplate reader, monitoring the reaction at $37^{\circ} \mathrm{C}$ every $2 \mathrm{~min}$ for a period of $70 \mathrm{~min}$. Results were expressed as relative trolox equivalent \pm standard deviation. Caffeic acid, chlorogenic acid and quercetin were used as experimental positive controls. All experiments were performed in triplicate.

\section{5,6-dihydroxy-7-methoxy- $\alpha$-dunnione (1)}

Orange solid; experimental $[\alpha]_{\mathrm{D}}{ }^{20}-101.5\left(c 0.03, \mathrm{CHCl}_{3}\right)$, calculated $[\alpha]_{\mathrm{D}}{ }^{20}-132 ; \mathrm{UV}-\mathrm{Vis}\left(\mathrm{CHCl}_{3}\right) \lambda_{\max } / \mathrm{nm}(\log \varepsilon) 268$ (4.01), 338 (3.78), 431 (3.43); $\mathrm{CD}$ (c $\left.0.001, \mathrm{CHCl}_{3}\right) \lambda_{\max }(\theta) 330$ (-43.0), 381 $(+10.7) ; \mathrm{IR}(\mathrm{KBr}) \mathrm{v}_{\max } / \mathrm{cm}^{-1} 3412(\mathrm{OH}, \mathrm{C}-6), 2923$ and $2851(\mathrm{C}-\mathrm{H})$, $1630(\mathrm{C}=\mathrm{O}), 1453$ and $1358(\mathrm{C}-\mathrm{H}), 1194(\mathrm{C}-\mathrm{O})$; for ${ }^{1} \mathrm{H}$ and ${ }^{13} \mathrm{C}$ NMR data, see Table 1; HRESIMS, calcd. for $\mathrm{C}_{16} \mathrm{H}_{17} \mathrm{O}_{6}[\mathrm{M}+\mathrm{H}]^{+}$: 305.1025 ; observed: $m / z 305.1010$ (error $=4.9 \mathrm{ppm}$ ).

\section{8-hydroxy-6,7-dimethoxy- $\alpha$-dunnione (2)}

Yellow solid; experimental $[\alpha]_{\mathrm{D}}{ }^{20}-158.4\left(c 0.01, \mathrm{CHCl}_{3}\right)$, calculated $[\alpha]_{\mathrm{D}}{ }^{20}-319 ; \mathrm{UV}-\mathrm{Vis}\left(\mathrm{CHCl}_{3}\right) \lambda_{\max } / \mathrm{nm}(\log \varepsilon) 239$ (3.77), 268 (4.09), 335 (3.88), 428 (3.34); $\mathrm{CD}$ (c 0.001, $\left.\mathrm{CHCl}_{3}\right) \lambda_{\max }(\theta) 330$ (-23.5), 381 (+5.0); IR $\left(\mathrm{CHCl}_{3}\right) \mathrm{v}_{\max } / \mathrm{cm}^{-1} 2923$ and $2850(\mathrm{C}-\mathrm{H}), 1640$ $(\mathrm{C}=\mathrm{O}), 1605(\mathrm{C}=\mathrm{C}), 1462$ and $1372(\mathrm{C}-\mathrm{H}), 1261$ and $1146(\mathrm{C}-\mathrm{O})$; for ${ }^{1} \mathrm{H}$ and ${ }^{13} \mathrm{C}$ NMR data, see Table 1; HRESIMS, calcd. for $\mathrm{C}_{17} \mathrm{H}_{19} \mathrm{O}_{6}$ $[\mathrm{M}+\mathrm{H}]^{+}:$319.1182; observed: $m / z, 319.1175$ (error $\left.=2.1 \mathrm{ppm}\right)$.

\section{RESULTS AND DISCUSSION}

The dichloromethane extract of tubers of S. reitzii "SC" yielded two new naphthoquinones (1-2) and three known compounds, which were identified as 6,8-dihydroxy-7-methoxy- $\alpha$-dunnione (3), ${ }^{11}$ 5-hydroxy-6,7-dimethoxy- $\alpha$-dunnione (4), ${ }^{7}$ and 6,8-dihydroxy-7methoxy-2-O-methyldunniol (5). ${ }^{12}$ (Figure 1). Compounds 4-5 had been previously reported in $S$. reitzii "PR" tubers; $;{ }^{7,8}$ however, other naphthoquinones isolated from $S$. reitzii "PR" were not found in S. reitzii "SC", including the compounds previously described with biological effects. All isolated compounds were analyzed by NMR (1D and 2D), and the data were compared with the literature.

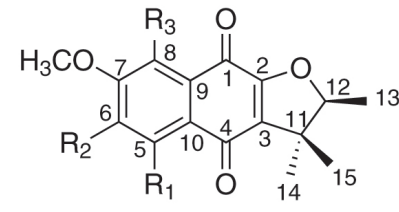

$\begin{array}{lll}R_{1} & R_{2} & R_{3}\end{array}$

$1 \mathrm{OH} \quad \mathrm{OH} \quad \mathrm{H}$

$2 \mathrm{H}$ OMe OH

$3 \mathrm{H} \quad \mathrm{OH} \mathrm{OH}$

$4 \mathrm{OH}$ OMe $\mathrm{H}$<smiles>C/C=C\C(C)(C)C1=C(OC)C(=O)c2c(cc(O)c(OC)c2O)C1=O</smiles>

5
Figure 1. Chemical structures of isolated compounds of S. reitzii "SC"

Compound 1 was isolated as an orange solid, with molecular formula $\mathrm{C}_{16} \mathrm{H}_{16} \mathrm{O}_{6}$ deduced from NMR data (Table 1) and positive HRESIMS $\left(\mathrm{m} / z, 305.1010[\mathrm{M}+\mathrm{H}]^{+}\right)$, which is consistent with nine indices of hydrogen deficiency. The IR spectrum of $\mathbf{1}$ showed absorption bands for hydroxy $\left(3412 \mathrm{~cm}^{-1}\right)$ and carbonyl groups $\left(1630 \mathrm{~cm}^{-1}\right) \cdot{ }^{11,13}$ In the ${ }^{1} \mathrm{H}$ NMR data, signals for one hydrogen $\left(\delta_{\mathrm{H}} 7.27\right)$, a methoxy group $\left(\delta_{\mathrm{H}} 4.01\right)$, an hydroxy group with an intramolecular hydrogen bond $\left(\delta_{\mathrm{H}} 12.53\right)$, a second hydroxy group ( $\delta_{\mathrm{H}} 6.02$, broad singlet), and a 2,3-dihydro-2,3,3-trimethylfuran group (quartet at $\delta_{\mathrm{H}} 4.60$, two singlets at $\delta_{\mathrm{H}} 1.29$ and 1.48 , and a doublet at $\delta_{\mathrm{H}} 1.45$ ) were observed (Table 1 ). Considering previous studies on S. reitzii "PR", these data suggested a naphthoquinone type dunnione (1,2-naphthoquinone) or $\alpha$-dunnione (1,4-naphthoquinone). These two types can be distinguished by analyzing the ${ }^{13} \mathrm{C}$ NMR data. The carbons from the quinone moiety are observed at around $\delta_{\mathrm{C}} 123(\mathrm{C}-3)$, 168 (C-4), 175 (C-2), and 181 (C-1) for dunnione-derivatives, while in $\alpha$-dunnione-derivatives they are observed at around $\delta_{\mathrm{C}} 130(\mathrm{C}-3)$, 158 (C-2), 177 (C-1), and 182 (C-4). Carbonyl groups involved in intramolecular hydrogen bonds are deshielded by 5-7 $\mathrm{ppm} .{ }^{13}$ The ${ }^{13} \mathrm{C}\left\{{ }^{1} \mathrm{H}\right\}$ NMR data of $\mathbf{1}$ showed peaks for 16 carbons, including two of carbonyl groups at $\delta_{\mathrm{C}} 177.1$ and 188.3. The first one was typical of $\mathrm{C}-1$ in the $\alpha$-dunnione framework, while the second had the chemical shift compatible with a carbonyl group associated with a hydroxy group, which we assigned to C-4. Therefore, the hydroxy group with an intramolecular hydrogen bond was located at C-5. Other signals characteristic of the quinone group in $\alpha$-dunnione-derivatives $\left(\delta_{\mathrm{C}} 129.7\right.$ and 159.7$)$ were also observed. In the HMBC spectrum, the hydrogen at $\delta_{\mathrm{H}} 7.27$ showed a cross-peak with $\mathrm{C}$-1, and was consequently located at $\mathrm{C}-8$. The hydrogen $\mathrm{H}-8$ and the hydroxy group at C-5 also exhibited cross-peaks with carbons at $\delta_{\mathrm{C}} 111.2(\mathrm{C}-10)$ and 
140.0 (C-6), while the methoxy group showed a cross-peak with a carbon at $\delta_{\mathrm{C}} 149.9$. These correlations indicated that the methoxy group was at C-7, and the second hydroxy group at C-6. These and remaining correlations in HSQC and HMBC (Table 1, Figure 8S) led to identification of $\mathbf{1}$ as 5,6-dihydroxy-7-methoxy- $\alpha$-dunnione.

Compound 2, a yellow solid, had the molecular formula $\mathrm{C}_{17} \mathrm{H}_{18} \mathrm{O}_{6}$, with nine indices of hydrogen deficiency, as deduced from NMR data (Table 1), and an ion at $m / z, 319.1175[\mathrm{M}+\mathrm{H}]^{+}$in the positive HRESIMS. The IR spectrum of $\mathbf{2}$ exhibited an absorption band for a carbonyl group $\left(1640 \mathrm{~cm}^{-1}\right) .{ }^{11,13}$ The ${ }^{1} \mathrm{H}$ NMR data of $\mathbf{2}$ were very similar to those of compound $\mathbf{1}$, showing signals for one hydrogen $\left(\delta_{\mathrm{H}} 7.25\right)$, a hydroxy group with an intramolecular hydrogen bond $\left(\delta_{\mathrm{H}}\right.$ $11.78)$, two methoxy groups $\left(\delta_{\mathrm{H}} 3.96\right.$ and 3.99$)$, and a 2,3-dihydro2,3,3-trimethylfuran group. These data suggested that the main difference between $\mathbf{2}$ and $\mathbf{1}$ was the presence of a methoxy group in $\mathbf{2}$ replacing a hydroxy group in $\mathbf{1}$. It was not possible to record the ${ }^{13} \mathrm{C}\left\{{ }^{1} \mathrm{H}\right\}$ NMR for $\mathbf{2}$, since only $0.8 \mathrm{mg}$ of it had been isolated. However, the ${ }^{13} \mathrm{C}$ NMR chemical shifts could be obtained from HSQC and HMBC spectra, which showed cross-peaks for carbons at $\delta_{\mathrm{C}} 131.1,158.3$ and 181.0 , indicating a $\alpha$-dunnione-derivative. Besides, in the HMBC spectrum, the methyl groups at $\delta_{\mathrm{H}} 1.26(\mathrm{C}-15)$ and $1.46(\mathrm{C}-14)$ showed correlation with $\mathrm{C}-3\left(\delta_{\mathrm{C}} 131.1\right)$, confirming the presence of a 1,4-naphthoquinone. However, unlike in $\mathbf{1}$, the hydrogen at $\delta_{\mathrm{H}} 7.25$ showed a cross-peak with C-4 $\left(\delta_{\mathrm{C}} 181.0\right)$ instead of $\mathrm{C}-1$ (around $\delta_{\mathrm{C}} 177$ for non-associated carbonyl group) in the HMBC. Therefore, this hydrogen was located at C-5, the hydroxy group with an intramolecular hydrogen bond was located at C-8, and the methoxy groups at C-6 and C-7. These and the remaining correlations observed in the HSQC and HMBC spectra (Table 1, Figure 15S) confirmed 2 as 8-hydroxy-6,7-dimethoxy- $\alpha$-dunnione (Figure 1).
In order to assign the absolute configuration of $\mathbf{1}$ and $\mathbf{2}$, the density functional theory (DFT) ${ }^{9}$ was applied, as previously reported for related compounds. ${ }^{4,8}$ Briefly, the theoretical optical rotations of specific enantiomers were calculated using DFT, and the calculated values were compared with experimental values, allowing the assignment of absolute configuration. Thus, the optical rotation calculated for 1 was 132, with negative signal for the $S$ isomer. Considering that the experimental value was -101.5 , compound 1 was represented as the isomer $12 S$. For compound 2, the optical rotation calculated was -319 for the $S$ isomer, and the experimental value was -158.4. Therefore, compound 2 also was assigned as $12 S$. In another approach, the electronic circular dichroism (ECD), experimental and calculated by DFT, of $\mathbf{1}$ and $\mathbf{2}$ were obtained. The experimental ECD curves of both compounds exhibited the same profile (a negative Cotton effect at $330 \mathrm{~nm}$ and a positive Cotton effect at $381 \mathrm{~nm}$ ), indicating the same absolute configuration. Furthermore, experimental and calculated ECD curves also were similar to each other, supporting the absolute configuration $12 S$ for compounds 1 and 2 (Figures 16S, 17S).

Compounds 1-5 contain at least one phenolic hydroxyl each, and consequently all the five are potential antioxidants. ${ }^{14}$ Therefore, the antioxidant capacity of compounds $\mathbf{1}, \mathbf{3}$ and $\mathbf{5}$, which were isolated with enough amount and purity, was evaluated using the ORAC-FL method. The three compounds displayed good antioxidant capacity, as their ORAC values were higher than 1.0 relative trolox equivalent (TE). Compound 1 was the most active, with ORAC of 4.83 TE, followed by compound $\mathbf{3}$ (ORAC $3.14 \mathrm{TE}$ ) and compound $\mathbf{5}$ (ORAC $1.39 \mathrm{TE}$ ) (Table 2). The antioxidant activity of $\mathbf{3}$ had already been previously determined by using the DPPH method. ${ }^{11}$

Antioxidant activity is dependent on the number and position of hydroxy groups, as well as on the type of framework and the

Table 1. NMR data for $\mathbf{1}$ and $2\left(400 \mathrm{MHz}, \mathrm{CDCl}_{3}\right)$

\begin{tabular}{|c|c|c|c|c|c|c|}
\hline \multirow{2}{*}{ position } & \multicolumn{3}{|c|}{1} & \multicolumn{3}{|c|}{2} \\
\hline & $\delta_{\mathrm{H}}$ mult. $(J$ in Hz$)$ & $\delta_{\mathrm{C}}$ & HMBC & $\delta_{\mathrm{H}}$ mult. $(J$ in $\mathrm{Hz})$ & $\delta_{\mathrm{C}}$ & $\mathrm{HMBC}$ \\
\hline 1 & & 177.1 & & & n.o. & \\
\hline 2 & & 159.7 & & & n.o. & \\
\hline 3 & & 129.7 & & & 131.1 & \\
\hline 4 & & 188.3 & & & 181.0 & \\
\hline 5 & & 149.3 & & $7.25 \mathrm{~s}$ & 104.4 & $4,7,9,10$ \\
\hline 6 & & 140.0 & & & 158.3 & \\
\hline 7 & & 149.9 & & & 140.3 & \\
\hline 8 & $7.27 \mathrm{~s}$ & 104.2 & $1,6,9,10$ & & 156.2 & \\
\hline 9 & & 123.7 & & & 110.7 & \\
\hline 10 & & 111.2 & & & 129.4 & \\
\hline 11 & & 45.0 & & & 45.3 & \\
\hline 12 & $4.60 \mathrm{q}(6.6)$ & 92.1 & 14,15 & $4.58 \mathrm{q}(6.6)$ & 92.1 & 14,15 \\
\hline 13 & $1.45 \mathrm{~d}(6.6)$ & 14.2 & 11,12 & $1.45 \mathrm{~d}(6.6)$ & 14.3 & 11,12 \\
\hline 14 & $1.48 \mathrm{~s}$ & 25.9 & $3,11,12,15$ & $1.46 \mathrm{~s}$ & 25.9 & $3,11,12,15$ \\
\hline 15 & $1.29 \mathrm{~s}$ & 20.7 & $3,11,12,14$ & $1.26 \mathrm{~s}$ & 20.6 & $3,11,12,14$ \\
\hline $5-\mathrm{OH}$ & $12.53 \mathrm{~s}$ & & $5,6,10$ & & & \\
\hline $6-\mathrm{OH}$ & $6.02 \mathrm{~s}$ & & & & & \\
\hline $8-\mathrm{OH}$ & & & & $11.78 \mathrm{~s}$ & & $7,8,9$ \\
\hline 6-OMe & & & & $3.99 \mathrm{~s}$ & 56.5 & 6 \\
\hline 7-OMe & $4.01 \mathrm{~s}$ & 56.7 & 7 & $3.96 \mathrm{~s}$ & 61.0 & 7 \\
\hline
\end{tabular}

n.o. = not observed. 
presence of other substituents different from hydroxyl. ${ }^{14}$ Accordingly, compounds 1, 3 and $\mathbf{5}$ showed different degrees of antioxidant capacity that can be associated with their structures. All compounds have two hydroxy groups, but in $\mathbf{1}$ these substituents are in ortorelationship, a structural characteristic that gives higher antioxidant activity than hydroxy groups in meta-relationship, as those in $\mathbf{3}$. Moreover, compounds $\mathbf{1}$ and $\mathbf{3}$ exhibited higher activity than the positive control caffeic acid, suggesting an important contribution of the $\alpha$-dunnione framework to the activity. In accordance, compound 5, a dunniol-derivative, showed minor antioxidant activity, in spite of having the same substitution pattern of $\mathbf{3}$ in the aromatic moiety.

Table 2. Antioxidant activitity by ORAC-FL assay of compounds $\mathbf{1}, \mathbf{3}$ and $\mathbf{5}$

\begin{tabular}{cc}
\hline Compound & ORAC-FL Assay $^{\mathrm{a}}$ \\
\hline $\mathbf{1}$ & $4.83 \pm 0.18$ \\
$\mathbf{3}$ & $3.14 \pm 0.01$ \\
$\mathbf{5}$ & $1.39 \pm 0.05$ \\
caffeic acid $^{\mathrm{b}}$ & $2.70 \pm 0.05$ \\
chlorogenic acid $^{\mathrm{b}}$ & $2.50 \pm 0.06$ \\
quercetin $^{\mathrm{b}}$ & $5.70 \pm 0.05$ \\
\hline
\end{tabular}

aRAC data expressed as relative trolox equivalent \pm standard deviation of triplicate assays; ${ }^{\mathrm{b}}$ Positive controls.

\section{CONCLUSIONS}

S. reitzii "SC" and S. reitzii "PR" share the characteristic of producing mainly naphthoquinones as less polar constituents, despite the geographic separation. However, plants from S. reitzii "PR" furnished, in previous studies, a higher number of naphthoquinones in significant amounts than S. reitzii "SC". Two naphthoquinones, with strong antioxidant activity, were isolated only from $S$. reitzii "SC". On the other hand, compounds with anti-inflammatory and cytotoxic activities, previously described in S. reitzii "PR", were not isolated from $S$. reitzii "SC". These results suggest that the biological properties of less polar extracts from $S$. reitzii tubers can be dependent on its collection area.

\section{SUPPLEMENTARY MATERIAL}

Data and spectra of NMR of isolated compounds from S. reitzii "SC" tubers are available in http://quimicanova.sbq.org.br, in PDF format, with free access.

\section{ACKNOWLEDGMENTS}

The authors are grateful to Dr. Mauro Peixoto (Instituto Plantarum, Nova Odessa, Brazil) for the help with collection and plant identification, to the Chemistry Department (UFSM) for Gaussian09, and to CAPES (Finance Code 001), FAPESP (process number 15/03726-8), and CNPq (process 304266/2017-5; 427859/20182; 309411/2019-0) for financial support. E. L. Sá is grateful to
Laboratório Central de Processamento de Alto Desempenho (LCPAD/ UFPR) for the computational facilities.

\section{REFERENCES}

1. Ferreira, G. E.; Ferreira, P. M. A.; Chautems, A.; Waechter, J. L.; Flora 2016, 222, 86 .

2. Chautems, A.; Dutra, V. F.; Fontana, A. P.; Peixoto, M.; Perret, M.; Rossini, J.; Candollea 2019, 74, 33.

3. Verdan, M. H.; Stefanello, M. E. A.; Chem. Biodiversity 2012, 9, 2701.

4. Sales, K. A.; Silva, E. F.; Figueiredo, P. T. R.; Costa, V. C. O.; Scotti, M. T.; Agra, M. F.; Tavares, J. F.; Silva, M. S.; Biochem. Syst. Ecol. 2018, 80, 76; Winiewski, V.; Serain, A. F.; Sá, E. L.; Salvador, M. J.; Stefanello, M. E. A.; Quim. Nova 2020, 43, 181.

5. Chautems, A. In Flora Fanerogâmica do Estado de São Paulo; Wanderley, M. G. L.; Shepherd, G. J.; Melhem, T. S.; Giulietti, A. M.; Kirizawa, M., eds.; Rima: São Paulo, 2003, v. 3; Hinoshita, L. K. R.; Dissertação de Mestrado, Universidade Federal do Paraná, Brazil, 2017. https://acervodigital.ufpr.br/handle/1884/47717.

6. Hoehne, F. C.; Sellowia 1958, 9, 37.

7. Soares, A. S.; Barbosa, F. L.; Rüdiger, A. L.; Hughes, D. L.; Salvador, M. J.; Zampronio, A. R.; Stefanello, M. E. A.; J. Nat. Prod. 2017, 80, 1837.

8. Silva, A. S.; Amorim, M. S.; Fonseca, M. M.; Salvador, M. J.; Sá, E. L.; Stefanello, M. E. A.; J. Braz. Chem. Soc. 2019, 30, 2060.

9. Hay, P. J.; Wadt, W. R.; J. Chem. Phys. 1985, 82, 284; Becke, A. D.; J. Chem. Phys. 1993, 98, 5648; Pedersen, T. B.; Hansen, A. E.; Chem. Phys. Lett. 1995, 246, 1; Frisch, M. J.; Trucks, G. W.; Schlegel, H. B.; Scuseria, G. E.; Robb, M. A.; Cheeseman, J. R.; Scalmani, G.; Barone, V.; Petersson, G. A.; Nakatsuji, H.; Li, X; Caricato, M.; Marenich, A.; Bloino, J.; Janesko, B. G.;Gomperts, R.; Mennucci, B.; Hratchian, H. P.; Ortiz, J. V.; Izmaylov, A. F.; Sonnenberg, J. L.; Williams-Young, D.; Ding, F.; Lipparini, F.; Egidi, F.; Goings, J.; Peng, B.; Petrone, A.; Henderson, T.; Ranasinghe, D.; Zakrzewski, V. G.; Gao, J.; Rega, N.; Zheng, G.; Liang, W.; Hada, M.; Ehara, M.; Toyota, K.; Fukuda, R.; Hasegawa, J.; Ishida, M.; Nakajima, T.; Honda, Y.; Kitao, O.; Nakai, H.; Vreven, T.; Throssell, K.; Montgomery-Jr., J. A.; Peralta, J. E.; Ogliaro, F.; Bearpark, M.; Heyd, J. J.; Brothers, E.; Kudin, K. N.; Staroverov, V. N.; Keith, T.; Kobayashi, R.; Normand, J.; Raghavachari, K.; Rendell, A.; Burant, J. C.; Iyengar, S. S.; Tomasi, J.; Cossi, M.; Millan, J. M.; Klene, M.; Adamo, C.; Cammi, R.; Ochterski, J. W.; Martin, R. L.; Morokuma, K.; Farkas, O.; Foresman, J. B.; Fox, D. J.; Gaussian 16, Revision C01, Gaussian Inc., Wallingford, CT, 2016.

10. Huang, D.; Ou, B.; Hampsch-Woodill, M.; Flanagan, J.; Deemer, E.; J. Agric. Food Chem. 2002, 50, 1815; Alencar, D. C.; Pinheiro, M. L. B.; Pereira, J. L. S.; Carvalho, J. E.; Campos, F. R.; Serain, A. F.; Tirico, R. B.; Hernandez-Tasco, A. J.; Costa, E. V.; Salvador, M. J.; Nat. Prod. Res. 2015, 30, 1088.

11. Cai, X.-H.; Luo, X.-D.; Zhou, J.; Hao, X.-J.; J. Nat. Prod. 2005, 68, 797.

12. Zhong, Y.-J.; Wen, Q.-F.; Li, C.-Y.; Su, X.-H.; Yuan, Z.-P.; Li, Y.-F.; Helv. Chim. Acta 2013, 96, 1750.

13. Inoue, K.; Ueda, S.; Nayeshiro, H.; Inouye, H.; Phytochemistry 1983, $22,737$.

14. Gulcin, I.; Arch. Toxicol. 2020, 94, 651. 